\title{
A role for the state in the digital age
}

Nagy Hanna ${ }^{1,2}$

Correspondence:

nagyhanna@comcast.net

${ }^{1}$ Wits University, Johannesburg,

South Africa

WWorld Bank, Bethesda, MD, USA

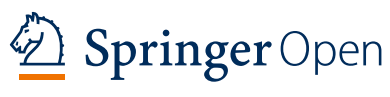

\begin{abstract}
Past and potential contributions of the state to innovation and the creation of the digital economy need to be understood now, more than ever. The state is under attack, and its role in innovation and technological transformation is being increasingly challenged and dismantled in many countries. This article takes an alternative view of state role in the digital age, one that is supported by historical evidence. The article examines the increasing demand for an entrepreneurial state and draws on lessons from pioneering countries. It shows the variety of roles and strategies that the state can play in creating the digital economy. These roles include nurturing a national digital transformation ecosystem and building an innovative and inclusive digital economy. These roles call for new state capabilities to fit with the demands of the digital age. This is a call for strategic learning and partnership, not for dirigisme and protectionism. The paper proposes an agenda for learning to master digital transformation and suggests that the appropriate role of the state must evolve in sync with a learning economy and society.
\end{abstract}

Keywords: Digital economy, Digital innovation, Digital entrepreneurship, Digital transformation, State role

\section{Background}

Past and potential contributions of the state to innovation and the creation of the digital economy need to be understood now, more than ever. This disconnect between the common belief among digital economy entrepreneurs and the realities and needs of the digital economy is increasing at a time when the challenges of digital transformation are rising and the new wave of digital technologies demand a much more policy activist, risk taker, market creator, and entrepreneurial state.

The state is under attack, and its role in innovation and technological transformation is being increasingly challenged and dismantled in the USA, and in other advanced economies. Market fundamentalists, and some Silicon Valley entrepreneurs, believe that business alone drives innovation and technological transformation. They believe that the wide diffusion of information, disseminated rapidly through mobile internet-connected devices and high-speed Internet access, have made markets more efficient and citizens more empowered, leaving little need or room for government to play in the digital age. The digital economy has become disconnected from the analog economy and from its keeper, the state. It is also true that the exponential rate of technological change, proceeding according to Moore's law, has outpaced the capacity of social, political, and many economic institutions to adapt.

(c) The Author(s). 2018 Open Access This article is distributed under the terms of the Creative Commons Attribution 4.0 International License (http://creativecommons.org/licenses/by/4.0/), which permits unrestricted use, distribution, and reproduction in any medium, provided you give appropriate credit to the original author(s) and the source, provide a link to the Creative Commons license, and indicate if changes were made. 
This article takes an alternative view of state role in the digital age, one that is supported by historical evidence. While innovation is not the state's main role in the society, and not the only role in enabling digital transformation, this article illustrates the state's historic ability in some countries to play an entrepreneurial role in society. Mazzucato (2013) shows in methodological detail of US history how the state not only facilitated the digital knowledge economy but also actively created it with a bold vision, enabling policies and targeted investments. For example, an in-depth examination of all the key technologies that make the phone so smart were government funded. Another example is the Internet which required a vision, a mission, and dynamic institutions with the ability to attract talent and create excitement around specific missions.

The article examines the increasing demand for an entrepreneurial state and draws on lessons from pioneering countries. It shows the variety of roles and strategies that the state can play in creating the digital economy. These roles include nurturing a national digital transformation ecosystem and building an innovative and inclusive digital economy. These roles call for new state capabilities to fit with the demands of the digital age. Finally, the paper proposes an agenda for learning to master digital transformation and suggests that the appropriate role of the state must evolve in sync with a learning economy and society.

\section{Lessons from US history and recent modernizers}

Innovation is both driven by and a driver of digital transformation. While innovation is not the state's main role in the society, and not the only role in enabling digital transformation, it can illustrate the state's historic ability in some countries to play an entrepreneurial role in society. US history shows that the state did not only facilitate the digital knowledge economy but also actively created it with a bold vision, enabling policies and targeted investments. For example, an in-depth examination of all the key technologies that make iPhone so smart were government funded: Internet, GPS, touch screen display, and SIRI voice-activated personal assistant (Mazzucato, 2013, chapter 5). Big projects such as the Internet required vision, mission, and dynamic institutions, with the ability to attract talent and create excitement around specific missions. Again, the US government played a prominent role in fostering an indigenous ICT sector, acting as a backer and vanguard, providing public venture capital for early commercialization of risky innovations, ensuring that intellectual property laws as enforced worldwide, and providing various tax and procurement support.

The US government has also driven innovation and data economy via open government data, data security, and Google's search engine. The European Union and the USA are struggling to set the policy and regulatory frameworks for such radical changes as the Internet of Things and the data economy. The recent violation of data privacy by Facebook, among other major platforms, and the frequent hacking of customer information of major corporations are heightening awareness of the tradeoffs and risks involved in leaving the cyber space unprotected and unregulated.

For emerging economies, the digital economy presents similar challenges where governments play varying activist roles, not only in innovation and adaptation of new waves of digital technologies but also in the assimilation and diffusion of these technologies across the whole economy. Digital technologies call for investing in complementary factors such as enabling policies, human resources, new institutions, 
and targeted infrastructure and platform investments, to secure the promised digital dividends. In best-practice countries, governments have played key roles, in partnership with business, to promote a dynamic ICT ecosystem, create a highly networked system of actors, and invest in the platforms and human capital required for the digital economy.

Among other leading examples in promoting and diffusing digital transformation are Singapore, Korea, Finland, Sweden, Israel, Estonia, and China. There is historical evidence that these governments have broaden and deepened their entrepreneurial and innovation roles, harnessing successive strategies and patient investments to build a dynamic digital transformation ecosystem, ubiquitous Internet access, digital platforms, digital literacy, digital leadership, and sustained commitment to transform. Just to illustrate, the Singapore case is outlined below (Table 1).

\section{A state fit for the digital age}

Managing digital transformation and creating the digital economy pose novel, multiple challenges for governments. These challenges arise from the fact that investing in

Table 1 The e-transformation journey of Singapore

Among the most distinguishing features of Singapore e-transformation journey are openness of the economy, openness to global knowledge, committed political and public service leadership, cumulative institutional learning, public-private collaboration, investment in a competitive information infrastructure, early attention to ICT literacy and user learning capability, clear cyber policies, and dynamic governance based on results orientation and accountability. Singapore excelled in disciplined application of ICT and is currently striving to excel in innovation. Despite of leapfrogging to the frontiers of international best practices, Singapore continues to learn from its shortfalls and adapt its ongoing plans accordingly.

Singapore adopted a holistic approach to developing and using ICT for its economic transformation. For example, ICT applications in the public sector have been planned and evolved, supported by complementary developments in information infrastructure, IT literacy and capability development, ICT industry sector, and ICT governance and institutions. E-government programs have been also based on a common foundation of shared infrastructure and services and deepened by sector-specific ICT-enabled transformations through elogistics, e-business, e-education, and e-health. Similarly, Singapore's ICT industry development was based on a comprehensive program that included ICT education, ICT diffusion to SMEs, parks and incubators for ICT ecosystems, risk capital finance and incentives for early adopters of $I C T$, and partnership with business associations and multinationals, among others.

The Singaporean Government worked on successive ICT plans since 1980, in partnership with the private sector. Each plan built on lessons learned from previous implementation, while adopting the latest best practices and technologies. Intelligent Nation 2015, or iN2015, is Singapore's current strategy to prepare the nation for the future. The plan outlines its vision to turn the country into "An Intelligent Nation, a Global City, Powered by Infocomm." Innovation, integration and internationalization are the basic thrusts. With inspiring visions of smart and knowledge-driven economy, Singapore built its capacity to innovate and create new business models and services and to integrate resources and capabilities across public and private institutions.

Singapore's experience offers important lessons. Political leadership and long-term commitment to e-transformation is one. Industry collaboration is another-getting the private sector to do more. Government created the opportunities and provided conducive working partnerships. It worked with industry on innovation, such as the Government Technology Experiments And Trials Program. Through constant dialog and experimentation, new ICT solutions were developed and adapted for innovative use. After two decades of nurturing the ICT industry, the industry has evolved as an important engine of growth. Government gradually shifted from planner and implementer, to a strategist and facilitator, creating conducive environment for ICT to thrive, grow, and diffuse. Other critical success factors are balancing investment in hard and soft infrastructure such as awareness and broad-based e-literacy, willingness to innovate to secure a first mover position, and investing early on in shared networks and data hubs.

Most critical to continued innovation and e-transformation has been the development of a governance system that can remain relevant and effective by smartly responding to emerging needs in a changing environment. This governance system includes:

- Having committed political and public service leaders with vision and high aspirations for the Singapore to set the tone for ICT strategies and institutions.

- Creating a learning environment, where people are consciously learning and seeking to apply new ideas and explore different ways of doing their work better.

- Creating innovative processes and agile structures by embedding change management practices, integrating change capabilities into management processes, and introducing process redesign, supported by effective participation and feedback mechanisms.

Source: "The e-Transformation Journey of Singapore" By Jeannie Chua, Chapter 2 in National Strategies to Harness Information Technology, by Nagy Hanna and Peter Knight (editors), 2012, Springer 
digital technologies and big data calls for new competencies from all actors in the economy. Moreover, investments in the digital sector alone do not secure the promised digital dividends. Such investments must be complemented by alignment with new development strategies, new policies, new skills, and new institutions where the state must play new roles.

The range of these roles includes setting national policies and priorities for the digital economy; supporting research and development of promising technologies; regulating and complementing market forces to ensure affordable access to the Internet; investing in human and organizational complements and institutional learning across all sectors and divides; leading public services transformation and governance; and creating state capabilities and institutions to plan, fund, and implement national digital transformation strategies. We elaborate only on a few.

\section{First, setting new policies for the digital age and aligning digital initiatives with national development strategy}

First and foremost, the state is tasked with creating new policies for the digital age. The fast pace of technology and the explosive generation of big data call for policy innovation and agile policy-making processes and institutions. The presence of strong network and scale economies and tendencies to create monopolies in the supply of digital platforms call for policies to manage these risks and ensure healthy competition. The state is called upon to develop and enforce digital sector policies to make the Internet universal, affordable, open, and safe, through securing market competition and effective regulation, managing spectrum and other scarce resources, promoting open government data, and keeping the Internet ecosystem open for content and applications. Policies are also needed to ensure online data privacy and cybersecurity.

State policy roles in the digital age extend to various forms of content and media platforms. The media is increasingly central to the functioning of markets and democracy. State policy aims to regulate, increasingly in a multi-platform environment, obligations, roles, and responsibilities of media service and content providers while creating, aggregating, and making available audiovisual content. Similarly, the state must work with stakeholders to set polices and regulations for data protection. The aim is to regulate data subjects' rights and data controllers and processers' obligations while collecting, processing, and using personal data. It also regulates transfer of data across national boundaries and roles and responsibilities in data-processing value chains.

Governments are required to manage the growing risks of concentration, inequality, and control that can undermine the promised shared prosperity. When the Internet and digital platforms deliver scale economies, but without competitive environment, the outcome could be excessive concentration and monopolies. When tasks are fast and automated but workers' skills are not continuously upgraded, the outcome will be greater inequality. When digital technologies help overcome information scarcity, but governments remain unaccountable, the outcome will be greater control rather than citizen empowerment and inclusion. To reduce these risks, policies and investments in the digital sector must be accompanied by complementary policy reforms in the non-digital (analog) sectors and socio-economic contexts where the new technologies are applied (World Bank 2016). 
As new digital technologies and platforms emerge, these policies must be continuously updated: witness the emerging privacy and security policy challenges arising from social media, big data, and the Internet of Things and the emerging employment challenges arising from fast advances in artificial intelligence and robotics. The exponential technology change (driven by Moore's law) coupled with scale effects is hard for policy makers to contemplate. These issues are increasingly complex, and their resolution requires multi-stakeholder participation to anticipate their impact and reflect societal values and priorities.

The state is also called upon to ensure that national digital initiatives are aligned and responsive to national development priorities. This alignment presents a continuous challenge that requires continuous communication, coordination, and strategy management among core policy-making agencies and the technical ministries responsible for the digital economy. Key ministries responsible for finance, macroeconomic management, and national development strategy must understand the imperatives of the digital economy while the technical ministries concerned with digital technologies, telecommunications, innovation, and education, among others must engage all stakeholders in the creative process of harnessing digital technologies for inclusive and sustainable development. Best examples are leadership from the top (Prime Minister or President) pushing the ministers and making them accountable as in Korea, Singapore, and Estonia. Consensus-making and education can also drive change from below, as in Finland.

\section{Second, supporting R\&D and playing an entrepreneurial role in researching and testing promising new digital platforms and technologies}

This R\&D will focus not only on the new technologies but also on their human complements and adaptation to local context. In many countries, R\&D will be about innovation in the local context, that is, monitoring global trends and adopting emerging digital technologies that are already available globally, and testing and adapting them to the local context before scaling up. The digital technology revolution has been the most broad and fast-paced technological revolution in human history. An activist, innovative, and risk-taking state is necessary to encourage sourcing these emerging technologies, support early adopters, and develop the complementary policies and test beds for effective absorption and localization. China is an example of this practice.

Third, extending the backbone telecommunications infrastructure and securing access to an inclusive and affordable internet

National broadband policies aim to accelerate the roll out of broadband infrastructure within a geography (region or a country) typically specifying an ambition in terms of expected broadband service speeds, service roll out time plan, and service adoption. They often also include public funding and public-private cooperation mechanisms. The state can provide a comprehensive national-level focal point for engaging stakeholders and guarding national and consumer interests, promoting broadband use, experimenting with measures prior to national adoption, providing a clearinghouse for successful projects, and evaluating what works and what does not.

Experience in advanced countries shows that successful broadband diffusion requires addressing both the supply- and demand-side issues. While supply-side policies focus 
on promoting network infrastructure for service delivery, demand-side policies aim to increase awareness and adoption of services. Promoting national build-out of broadband networks will likely require governments to pursue multiple strategies, depending on local circumstances. However, certain policy approaches may be globally applicable. The private sector is generally accepted as the primary driver of broadband development in most countries. In the developed countries and some developing ones, a majority of private investment may come from within the nation. In less endowed countries, attracting foreign private investment-through appropriate incentives, a clear regulatory and legal environment, and a good development plan-may be important components of a broadband strategy. Governments can also accelerate the deployment of networks and improved competition by allowing, and occasionally, even requiring infrastructure sharing.

To alleviate the connectivity problem in the short-to-medium term, countries have been using or experimenting with the following methods: (a) devising special policies and incentives to encourage infrastructure development in rural areas; (b) building subsidized networks for groups of users whose interconnectivity is crucial for economic and social development, i.e., government, academic, R\&D and educational institutions; and (c) promoting shared access to Internet and other ICT tools for disadvantaged areas. Many states are innovating business models for addressing internet access gaps to poor communities and rural areas in partnership with private operators, local entrepreneurs, and civil society, as in Brazil.

\section{Fourth, investing in human and organizational complements and institutional learning across all sectors, to secure digital dividends and inclusion}

Substantial investment is needed to implement organizational changes, process innovations, and other intangible digital assets (such as digital data and content) to realize the promised digital dividends. These capabilities involve deep changes in skills, roles, norms, routines, teamwork, cross-sector partnerships, and leadership and managerial practices.

Working with the relevant stakeholders, the state can play critical roles in ensuring the wide and effective diffusion of digital technologies among lagging sectors and poor communities. Small and medium enterprises (SMEs) need state support programs for adopting the new digital technologies and for learning to transform their businesses and practices. Adoption of new technologies by SMEs involves significant risks, learning, change management, and capability development. OECD countries have been supporting programs to promote the adoption of new waves digital technologies among SMEs, including industrial extension services and creating markets for business development services.

Without state intervention, the digital divide will grow and further reinforce the increasing economic divide within and among nations. The state is called upon to counter these divides through affordable access to the Internet and digital technology tools, universal digital literacy, and developing local content, informational capabilities, grassroots innovation networks, and complementary skills. The challenges of eradicating extreme poverty and building inclusive societies are not primarily technological. Addressing these challenges requires better understanding of the poor, their context, their resources, the difficulties they face, and the information they lack. It requires building the capacity of local information intermediaries and grassroots organizations. It requires piloting and experimenting. It demands that governments create the 
enabling environment to bridge the digital divide. It requires better ICT research that addresses the conditions of poor communities. In leading such efforts to bridge the digital divide, the state must work with civil society and community organizations, local government, business associations, universities, and philanthropic organizations.

\section{Nurturing a digital transformation ecosystem}

Governments would be advised to take a holistic view of national digital transformation and deal with digital transformation as a highly interactive ecosystem, requiring shared vision, agile strategies, sustained commitment, and institutionalized collaboration. Digital technologies, infrastructures, platforms, applications, and big data are highly interdependent and should be treated as a dynamic ecosystem (Fig. 1). Maximizing digital dividends requires assessing and nurturing this digital ecosystem, and tapping into its synergies at the national, regional, sector levels. The state cannot shy from the growing and complex requirements of holistic digital transformation, if it is to compete globally in the digital age.

The digital transformation ecosystem can be conceived as composed of interdependent elements (Fig. 1):

(a) Enabling policies and institutions: These include the necessary tools of the state to coordinate and synergize the whole digital transformation ecosystem. They constitute the environment that will enhance interaction among all elements of the transformation process. They promote the effective supply and use of ICT in all sectors of economy and society. Enabling policies and institutions are essential to fostering trust in the digital economy. They are shaped by shared vision and leadership.

(b) Human capital: Skilled human resources are at the heart of the digital revolution, as both users and producers; they include policy, technical, and change management skills as well as broad information and digital literacy, and techno and data entrepreneurship.

(c) ICT and data industry: A dynamic digital industry ecosystem is necessary to adapt globally available technology solutions to local needs, manage and maintain technological infrastructure, develop digital local content and solutions, and effectively partner with global suppliers of ICT. In particular, local software

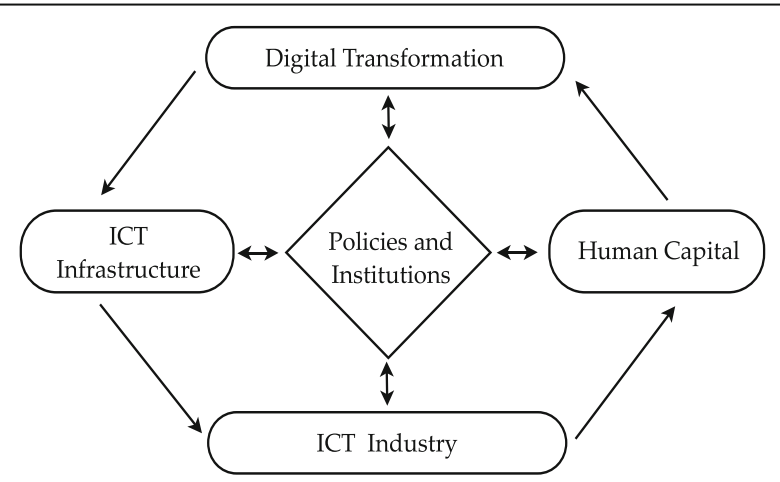

Fig. 1 The digital transformation ecosystem 
development and data analytics capabilities represent a core competency that enables wide and effective domestic use of digital technologies.

(d) Digital infrastructure: This refers to affordable and competitive communication infrastructure, including affordable access to the Internet and ICT tools, broadband, key platforms such as cloud computing and digital payment systems.

(e) Digital transformation applications: This component includes digital technology applications and complementary investments in institutional capabilities to transform key ICT-user sectors of the economy, including digital government, digital commerce and finance, and digital transformation of other priority economic sectors.

This digital transformation ecosystem functions within the broader socio-economic context of the nation. In particular, broad policies concerning trade, education, business environment, and innovation play crucial roles in enabling ICT adoption, effective use, digital transformation, and economic impact. Given the externalities and network effects of ICT investments, tax incentives or subsidies, appropriately targeted, can also play a role in promoting adoption.

An example of how the state is intertwined with other actors in an ecosystem is in its role in promoting digital commerce (Fig. 2). Online commerce has become an entry point for increasing export, innovation, and business transformation. It provides a platform for innovations in business processes, relationships, products, and services. Some states have therefore initiated e-commerce diffusion programs to help early adopters and SMEs and increase the scale and impact of this innovation in selected sectors or economy-wide.

An ecosystem approach can be helpful in designing holistic diffusion programs for digitally transforming small businesses and in mobilizing the relevant stakeholders to fund and sustain them. These programs would focus on actual usage and payoffs from e-commerce, rather than focusing solely on digital investment. They would be tailored to country context, to address policy and institutional factors, such as payment systems, privacy and data security, legal protection for online transactions, customs and trade compliance procedures, and Internet governance. They should address issues of access to Internet and broadband, and the diverse forms of digital divide. They may also address those infrastructural issues (e.g., postal, transport, logistics, electricity) that impact SMEs' e-commerce most adversely. And perhaps most important to SMEs, diffusion programs can promote capability development and advisory services to SMEs to leverage and integrate e-commerce adoption into their business strategies and practices. Effective programs are typically sponsored by the state, in collaboration with local governments, and trade and business associations.

Figure 2 sums up the various factors that influence the adoption and use of e-commerce, and overall e-commerce ecosystem of a country; this ecosystem view should guide the design of e-commerce diffusion programs.

\section{Building an innovative digital economy}

The digital technology revolution has been the most broad and fast-paced technological revolution in human history, causing deep disruptions in all types of industries and services and requiring major changes and innovations in policies, institutions, and skills. 


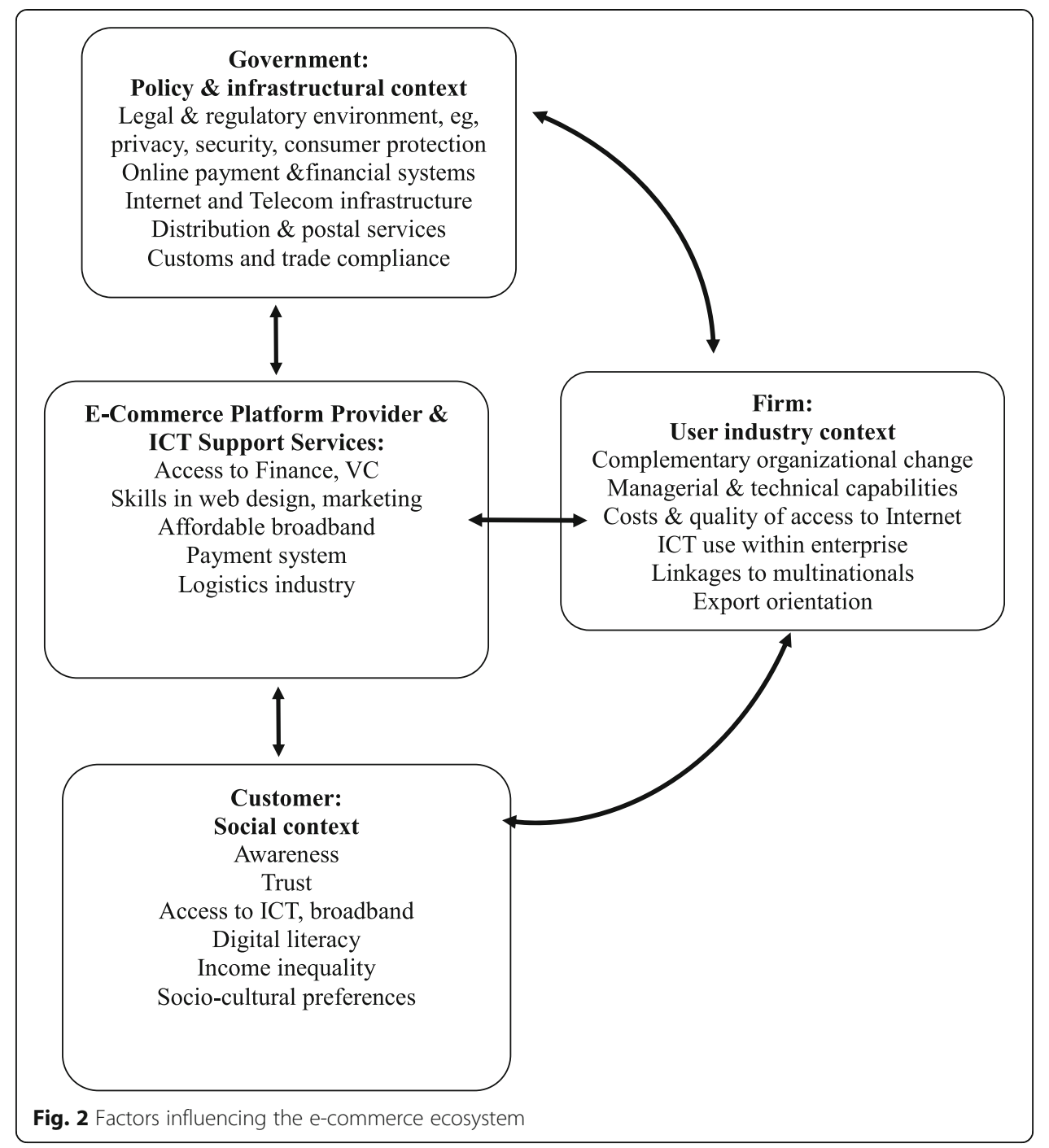

An innovative, risk-taking state is critical to researching the new technologies, support early adopters and broad diffusion, encourage effective procurement of these technologies, promote open data and analytics practices, and develop the complementary policies and test beds for effective absorption and local appropriation.

The state can play an entrepreneurial role in researching and testing promising new digital platforms and technologies for the public sector and the whole economy. This $R \& D$ function focuses not only on the new technologies but also on their human complements and adaptation to local context. In many countries, $R \& D$ will be about innovation in the local context, that is, monitoring global trends and adopting emerging digital technologies that are already available globally, and testing and adapting them to the local context before scaling up.

Government procurement of digital technologies and services play an important role in promoting competition and innovation among suppliers of digital technologies. Advanced economies have used government procurement to promote open standards, best practices in ICT adoption and process reengineering. They have also devised programs and practices to nurture small and medium local suppliers of the new technologies. Local 
governments are at disadvantage of dealing with global ICT suppliers and often lack the internal capacity to assess new technologies for their local needs. Progressive central governments continue to play a leading role in working with local and city governments to procure and test the technologies and their adaptation to local contexts. They also facilitate knowledge management and information sharing across municipalities to promote effective adoption of innovations and applications across the public sector and levels of government.

The state can play a leading or catalyst role in developing the data economy and the innovations associated with using open data and big data across the economy. Open government data makes public sector data technically and legally open for use as part of an emerging global culture of disclosure and transparency. Along with big data and analytics, OGD is providing visibility and access to an unprecedented amount of information about the government, business, and population. OGD is expected to increase transparency and accountability of public agencies while strengthening citizen participation and, along the way, allow users to create, or even co-create, economic value from public sector information. As governments engage in creating the open data ecosystem, they are pressured to transform and innovate their own practices and services. OGD, therefore, propels innovation in data-generated services, increases efficiency of existing services, and improves governance, policy- and decision-making.

Many factors influence the pace and magnitude of realizing the benefits of the open data ecosystem. OGD is not just about opening the digital data stores of government. It demands the development of open government policies, laws, skills, leadership, and culture, as well as citizen engagement through various forums. It calls for supply-side as well as demand-side measures. Promoting citizen engagement without associated ICT-enabled reforms and change management within governments may run the risks of raising unrealistic expectations and fanning discontent (Hanna and Knight, 2011a and b). OGD can thrive only through partnerships between public agencies, application and content developers, and civil society organizations, creating a vibrant open-data ecosystem.

The state plays a key role by developing policies and institutions to support the evolution of the entire OGD ecosystem. The USA adopted the "open by design" principle-an open government data policy. The federal government also created new posts of Chief Data Officers in the federal agencies. A structured dialog among public agencies (major suppliers of OGD) and the major users is increasingly used to understand the demand side and prioritize the development and openness of federal datasets. In a few years, an open data revolution has spread to many countries, making government data open by design. But the potential is huge, as effective demand and analytic capabilities takes time to build up.

Big data and analytics promise to fuel the twenty-first century digital economy. Breakthroughs in data-capturing technologies, geo-mapping, open source mobile apps, social media, data standards and storage, visualization, analytic tools, and optimization sciences have created opportunities for fact-based decision-making and fast-learning cycles. Mobile data, for example, help service providers understand client behavior and enable user-centric solutions among others in areas as diverse as education, health, finance, and agriculture. To turn mobile data into a digital economy fuel, a number of ecosystem elements must be put in place-privacy and security for users and incentives for government, civil society, and private sector to share and use data for the benefit of society. 
The state can play a lead role in strengthening the relationships among various actors of the big data ecosystem and prioritize and sequence steps to manage big data analytics for public policy and program management (Fig. 3). The government can catalyze the development of this ecosystem through the opening of its own datasets and the active facilitation of use and dissemination. Policy makers can set the legal frameworks governing data privacy and security, establish data commons, and incentivize public agencies to continually improve the data they make available.

One of the most promising use of big data is in the development of smart cities, where instrumentation, interconnection, and intelligence are combined to create smart infrastructure, efficient utilities, customer-centric public services, citizen-driven innovation, and smart city planning and management. For example, Singapore City leadership developed and executed successive plans to make the city efficient in its service delivery, water use and re-use, and urban transport and mobility. Singapore continues to improve its services, innovate new ones, and provide a test bed for new waves of digital technologies. New York City government worked closely with the business sector to nurture an innovation-driven startup ecosystem and developed an open data platform for sharing information on all city activities and a host of digitally enabled measures to support innovation in services. Barcelona' smart city initiatives focused on open data for smart governance, digital innovation clusters, intelligent transportation systems, and digital literacy, smart living, and environmental sustainability. In partnership with local universities, several European cities are providing living labs: networks, forums, and spaces to allow innovative and civic communities to emerge and thrive.

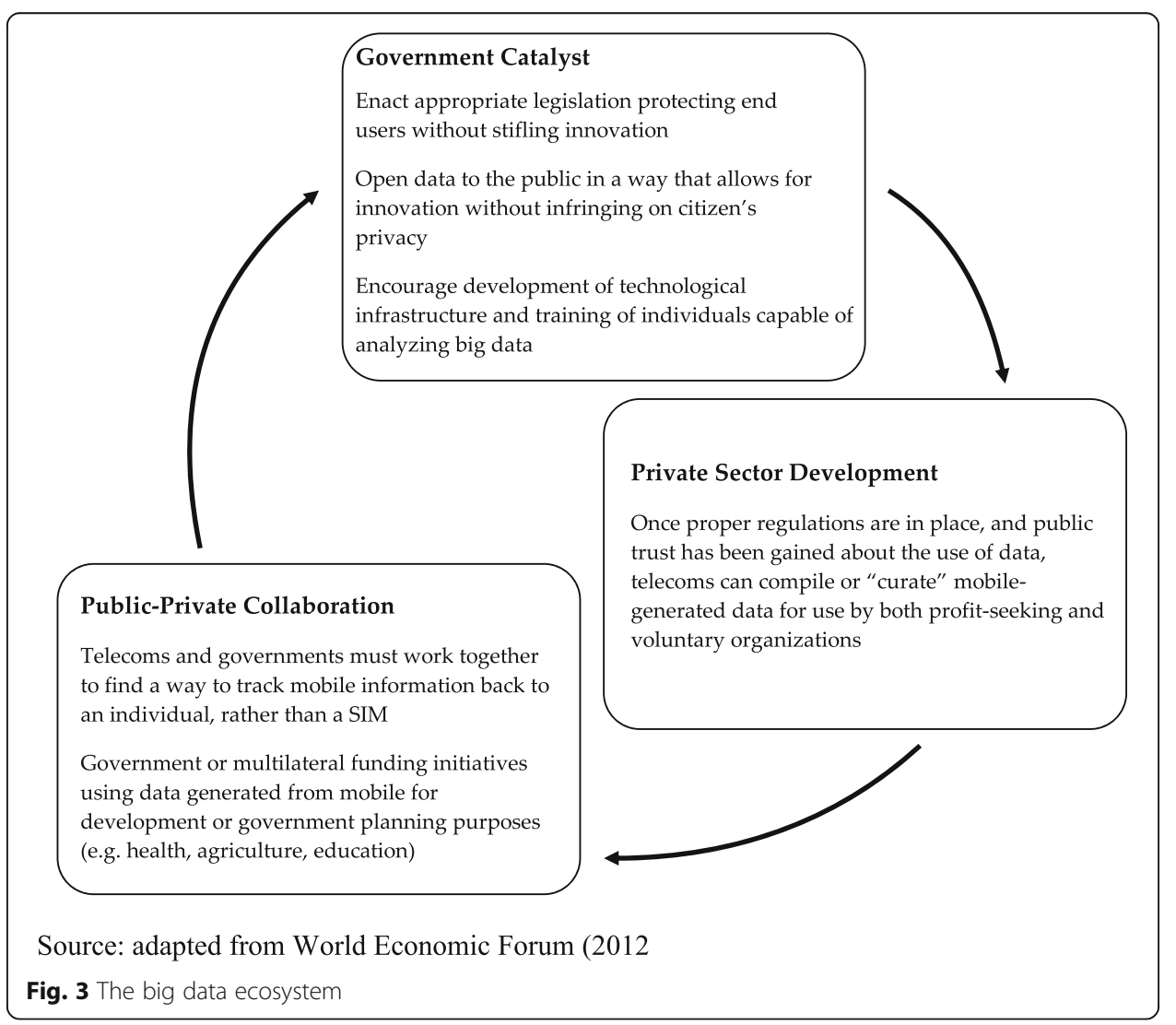


Local leadership to develop smart cities is also spreading to developing countries. The big city of Wuhan, China (10 million population) adopted intelligent transport system solutions to improve the overall efficiency of the city and to build capacity and platforms to understand and analyze the big data being generated from its instrumented infrastructures. Gran Concepcion, Chile (1 million population), is an example of an innovative city emphasizing governance, open data, jobs and competition. Medellin, Colombia, is an example of a city seeking to become more resilient and safe by using digitally enabled integrated response to emergencies. It also created a mobility control center to monitor traffic, logistics, predictive analytics, and systems of communication with public officials, as well as for generating information for citizens through various electronic channels. Finally, digital India is an example of a large but relatively poor country, with ambitious plans to catch up and transform its cities to meet service demands and sustainability challenges in efficient and smart ways. In all these examples, it has been the city mayors and local governments that are taking the lead, in collaboration with businesses, civic societies, and central governments, to create digitally enabled efficient, inclusive, and resilient cities and innovative digital economies.

\section{Building an inclusive digital economy}

The state is concerned with the rising economic inequality and the possible role of digital technologies in alleviating or reinforcing this trend. This role is especially important for democracies to survive and thrive. This requires much innovation and experimentation to make these technologies accessible and affordable to poor communities in particular. As ICT is a general-purpose technology, its utility and impact depend on user capabilities and various contextual and complementary factors that are often lacking among poor communities. Governments therefore endeavor to promote an inclusive information society by supporting frugal and pro-poor innovation.

One approach to promote social inclusion and community empowerment is via grassroots, demand-driven innovation funds. National and local governments can encourage universities and business to experiment with digital technologies to expand opportunities for the poor. One example is Malaysia's Demonstrator Application Grant Scheme to stimulate innovative use of ICT for social development. Pro-poor public policies may also promote partnerships among NGOs, MNCs, universities, and local and state government agencies to understand the potential role of digital technologies in empowering poor communities, delivering tailored services, developing relevant local content, and building the capabilities of social intermediaries. There are substantial unrealized synergies among these actors that can help innovate for the base of the pyramid.

Funds in support of ICT for socially driven, bottom-up innovation can transform the capabilities of communities, the performance of their local institutions, the functioning of their markets, and the livelihoods of their poor. These funds may not generate breakthrough technological innovations. But they can mobilize local communities, businesses and NGOs, to co-create digital solutions that are particularly responsive to these target groups and their diverse local contexts.

Digital identification systems are being pioneered on a massive scale in several developing countries. It promises profound transformation in delivering services in inclusive and secure ways to whole populations. India is building a national biometric 
database that gives a unique ID to every citizen, covering 1.2 billion people. Currently, hundreds of millions of Indians are barely visible to the state, and less than half of the population have a birth certificate, usually the poorest. This massive experiment in a national digital platform is now open to use for the reliable delivery of financial and government services. It has been first used for targeted social cash transfer programs, the National Rural Employment Guarantee Act, with savings for government in the billions of dollars by removing ghost employees from government payroll and unentitled beneficiaries from social programs.

The state played an entrepreneurial role in India and several other countries, by taking the risk of investing on a large scale in a new and complex infrastructure, a platform that is open and secure for delivering services for both public and business services. While holding the potential to improve the efficiency of all kinds of social and financial services, this platform will give all citizens access to what they are entitled, including access to vital social protection schemes. It provides scale, speed, quality, transparency, cost-effectiveness, and innovation platform. It offers a powerful platform for expanding social inclusion and experimenting with new services.

\section{Creating digital government capabilities}

The state needs to leverage the digital revolution to make the public sector more capable and responsive, to expand citizen participation in service delivery and policy making and enhance accountability and citizen voice in service delivery. Digital transformation of government and its services is no longer an option. Governments all over the world face a potent combination of challenges today: increasing government budget constraints; rising citizens expectations for responsive public services; growing inequalities in access, incomes, and opportunities; rising popular demand for transparency and accountability; declining trust in government for failing to deliver on promises; and the need to compete in a fast-moving, knowledge-based global economy.

Transforming a government is about redefining the relationship between the government and its citizen (and business) to become customer-centric. Introducing a citizen-centric approach to a government is similar to introducing a disruptive technology into a traditional system. It is a paradigm shift in perspective, with the government providing services in ways that make sense from the client's point of view. Indeed, it turns the traditional model of government on its head. It is a shift from inside-out to outside-in, starting from the client, not the bureau. The traditional model is centered on the agency providing the service-with service levels, timing, payment mechanisms, and procedures built around the agency. A client-centric government makes the citizen the center of all activities-government services must be available anytime the citizen demands them, anywhere the citizen wants to receive them, and through whatever medium the citizen wants to use. Countries such as Canada, Singapore, the United Kingdom, and the Nordics have adopted this perspective in their digital government programs.

A starting point for a transformation journey is to create a motivating vision of a desirable future government. Visions of the future government should capture cutting-edge practices in reforming public sector agencies such as results-based management, putting citizens at the center, and delivering service on demand. They should reflect citizen aspirations for transparent, accountable, and participatory government. 
This vision should be clearly communicated to all stakeholders. Broad mobilization and clear accountabilities to citizens for public service performance are key to counter resistance to change from organized groups with strong vested interest in the status quo. Investments in e-government can have the greatest impact when combined with civil service reform: digital government involves not only introducing digitally enabled process reengineering, but also transforming the skills, incentives, and culture of the civil service to increase professionalism, collaboration, accountability, and transparency. Achieving these changes requires substantial investment in transforming routines, organizations, and power relations-a long-term investment that can be sustained only with a clear, shared, motivating vision.

Fundamental shifts in government have never been easy to realize. These shifts are from closed, hierarchical, turf bound, and inward orientation to open, decentralized, service-oriented, and connected organization They cannot be done by technology alone. They involve changes in attitudes, skills, and deep-seated routines and organizational culture. A well-sequenced and prioritized series of e-government initiatives, guided by a whole-of-government approach to digitalization and information sharing, complemented with public sector reforms and aligned incentives among stakeholders can set in motion the necessary learning and the momentum and commitment to overcome such barriers to change.

Many of the factors that drive digital transformation in various social sectors like education and health are similar to those required for transforming the whole of government. Basic among them are a shared vision of the future of the sector, support to sector policy reforms, leadership and competencies to manage transformational change, demand mobilization and consumer education; continuous assessment of performance of service delivery, and systematic dealing with the gaps in the digital ecosystem of the target sector. The government plays a dual role in shaping the interactions among actors and components of the digital transform ecosystem: as policy and rule maker to create the enabling environment, and as a strategic investor in digital technology applications and data in support of transformation of the target sector.

Aligning sectoral policies and incentives with digital transformation initiatives is essential to realize a sector's digital transformation potential. These complementary policies are likely to vary across sectors. For public services such as education and health, the key complementary factors are leadership, accountability, and governance within the sector and effective citizen demand and participation. The state must lead such alignment and invest in these complementary factors. For private sector-driven services, such as financial and business services, the important factors are regulation, competition, managerial capability, skilled work force, and industrial organization, and here, the state plays enabling and facilitating roles. For all sectors, incentives and contexts matter most. The lack of state leadership in pursuing sectoral reforms and effective complementary policies often lead to wasted digital investments and stunted or unsustainable transformation.

New state capabilities and institutions are required to plan and implement national digital transformation policies and strategies. These capabilities are increasingly important to engender shared vision, mobilize a long-term commitment to digital transformation, and integrate ICT opportunities and investments into national, regional, and sectoral development strategies. The state may partner with the private sector to invest 
in broadband infrastructure and shared digital platforms. It must lead in setting fast-paced policy reforms, engaging stakeholders, pursuing partnerships with civil society and the private sector, securing wide access to the Internet and digital technology tools, and enabling bottom-up initiatives, local adaptation, and social learning. These old and new roles call for building new competencies within the public sector and for partnering with private sector and civil society.

\section{Discussion: Learning to master digital transformation}

Key lessons can be learned from examining and comparing emerging best practices of states in leading digital transformation (Hanna and Knight 2011a and b). Research and country studies are needed to improve our understanding of state role in the digital economy, and how governments are learning to fulfill this role. This research should help improve current practices of governments and of development assistance agencies. A proposed learning agenda may include the following:

- What measures can help align and integrate the national digital transformation strategy with the country's development strategy, priorities, and challenges?

- What complementary factors will be needed, economy-wide and in each sector, to realize the digital payoff? How can policy makers secure attention to the softer aspects of transformation, like managing digital disruptions and developing the skills and culture necessary for the digital age?

- How can local initiative and innovation be supported and aligned with national strategic priorities and programs to create a virtuous cycle of innovation and societal learning?

- How can policy makers support experimentation, innovation, and adaptation to enable agile learning and participatory evaluation?

- How can leaders and stakeholders strengthen the digital transformation ecosystem, and exploit the potential synergy among its elements?

- How should policymakers engage stakeholders and pursue partnerships to create a shared vision, comprehensive diagnosis, coherent policies, and effective implementation?

\section{Conclusion}

The digital age asks more of governments than ever before. Innovation economy demands innovative government, not only to transform itself into an agile and responsive actor but also to create the necessary policies and platforms to facilitate the workings of a dynamic digital economy. Governments must build their capacity over time and learn to play new and expanded roles fitting with the digital age.

The appropriate role of government in the economy is not static. It must evolve as the economy and technology do. This evolution has to take a faster pace than has been in the past in response to the fast-paced digital revolution and arising novel policy challenges. There is no one-size fits-all for government role in the digital age. Understanding the political economy of the country, local competencies in the public and private sectors, and past history of government successes and failures can provide a guide to a progressively agile and entrepreneurial government, fit for the digital age. 
States can learn to create learning societies (Stiglitz and Greenwold 2014). They can foster mutual learning through partnership with the private and social sectors to build the learning society. The state can learn to pick winners, rather than losers picking the state. The government can learn to work with startups to both foster competition and regulate against rising monopolies. Conversely, by doubting the state's ability to work for public interest and be an innovative agency in society, and only blaming it for some of its failures, the state would be prevented from learning, become risk averse, and be easily captured by lobbies, monopolies, and the status quo. Mastering digital transformation by governments, businesses, and societies is likely to be the defining the core competency of the twenty-first century. The state cannot afford to be left out.

Authors' contributions

The author read and approved the final manuscript.

\section{Author's information}

Dr. Nagy K. Hanna is a global expert on national innovation, smart cities, and digital transformation strategies. He is advisor, educator, author, public speaker, and thought leader on innovation policies, institutions, and strategies, over 40 years of experience in advising policy makers in developing policies, institutions and infrastructures in support of innovation and entrepreneurship ecosystems, digital economy, smart cities, knowledge industries, and private sector development. He was the World Bank's first senior advisor on digital and innovation economy.

Currently, Dr. Hanna advises countries and aid agencies on developing institutions and leadership capabilities for enabling firm- and cluster-based innovation, creating innovation funds and hubs, and integrating innovation programs into city and national development strategies. He is a Visiting Professor at Wits University, South Africa, published extensively on innovation and digital economy policies and institutions and the role of government and aid agencies in the digital age.

While a senior staff of the World Bank, spanning 30 years, he led many World Bank-funded digital innovation programs. Pioneered the Bank's advisory services and lending for integrated digital transformation. He surveyed leadership institutions for the knowledge economy in 40 countries. Surveyed and advised on strategic planning practices and management development systems. Dr. Hanna has a Ph.D. in business and economics from the University of Pennsylvania.

\section{Competing interests}

The author declares that he/she has no competing interests.

\section{Publisher's Note}

Springer Nature remains neutral with regard to jurisdictional claims in published maps and institutional affiliations.

Received: 17 June 2018 Accepted: 28 June 2018

Published online: 16 July 2018

References

Hanna, NK, \& Knight, P (2011a). Seeking transformation through information technology: strategies for Brazil, China,

Canada and Sri Lanka. New York: Springer.

Hanna, NK, \& Knight, P (2011b). National strategies to harness information technology: seeking transformation in

Singapore, Finland, the Philippines, and South Africa. New York: Springer.

Mazzucato, M (2013). The Entrepreneriial State. London: Anthem Press.

Stiglitz, J, \& Greenwold, B (2014). Creating a learning society. New York: Columbia University Press.

World Bank (2016). Digital dividends. World Development Report 2016. Washington, DC: World Bank. 